\title{
BMJ Open Essential fracture and orthopaedic equipment lists in low resource settings: consensus derived by survey of experts in Africa
}

Yuen Chan, ${ }^{1}$ Leonard Banza, ${ }^{2}$ Claude Martin Jr, ${ }^{3}$ William J Harrison ${ }^{1}$

To cite: Chan Y, Banza L, Martin $\mathrm{Jr}$ C, et al. Essential fracture and orthopaedic equipment lists in low resource settings: consensus derived by survey of experts in Africa. BMJ Open 2018;8:e23473. doi:10.1136 bmjopen-2018-023473

Received 22 April 2018 Revised 25 July 2018 Accepted 30 July 2018

\section{Check for updates}

\section{(c) Author(s) (or their} employer(s)) 2018. Re-use permitted under CC BY-NC. No commercial re-use. See rights and permissions. Published by BMJ.

${ }^{1}$ Department of Trauma and Orthopaedics, Countess of Chester Hospital NHS Foundation Trust, Chester, UK ${ }^{2}$ Department of Orthopaedics, Kamuzu Central Hospital, Lilongwe, Malawi

${ }^{3}$ AO Alliance, A0 Alliance

Foundation, Davos, Switzerland

Correspondence to

Yuen Chan; y.chan1@nhs.net

\section{ABSTRACT}

Introduction Low/middle-income countries (LMICs) have a growing need for trauma and orthopaedic (T\&0) surgical interventions but lack surgical resources. Part of this is due to the high amount of road traffic accidents in LMICs. We aimed to develop recommendations for an essential list of equipment for three different levels of care providers. Methods The Delphi method was used to achieve consensus on essential and desirable T\&0 equipment for LMICs. Twenty experts with T\&0 experience from LMICs underwent two rounds of questionnaires. Feedback was given after each round of questionnaires. The first round of questionnaire consisted of 45 items graded on a Likert scale with the second round consisting of 50 items. We used an electronic questionnaire to collect our data for three different levels of care: non-operative-based provider, specialist provider with operative fracture care and tertiary provider with operative fracture care and orthopaedics.

Results After two rounds of questionnaires, recommendations for each level of care in LMICs included 4 essential equipment items for non-operative-based providers; 27 essential equipment items for specialist providers with operative fracture care and 46 essential equipment items for tertiary providers with operative fracture care and orthopaedic care.

Conclusion These recommendations can facilitate in planning of appropriate equipment required in an institution which in turn has the potential to improve the capacity and quality of T\&O care in LMICs. The essential equipment lists provided here can help direct where funding for equipment should be targeted. Our recommendations can help with planning and organising national T\&0 care in LMICs to achieve appropriate capacity at all relevant levels of care.

\section{INTRODUCTION}

Surgery is an essential component of healthcare. Two-thirds of the world's population do not have access to safe, affordable and timely surgical care and 16.9 million people die from conditions that require surgical care each year. Most of these deaths are from low/ middle-income countries (LMICs). ${ }^{12}$ From the WHO global health observatory data,
Strengths and limitations of this study

- Our experts are all from Africa with expertise in working in low/middle-income countries (LMICs) and, therefore, are able to give the breadth and depth of experience needed to assess which equipment are reasonable and essential.

- The Delphi technique was used to achieve consensus in a highly structured and controlled manner.

- Multiple factors affect access to, and quality of care for, trauma patients and this study only looks at the need to agree on and provide appropriate equipment.

- We did not specify the number of each equipment item that would be required as this can vary between institutions.

- We used the standard Delphi technique and not the modified technique which encompasses a face-toface meeting between the experts.

LMICs had higher road traffic fatality rates per 100000 population (24.1 and 18.4, respectively) compared with high-income countries (9.2). ${ }^{3}$ Trauma kills more people than HIV/AIDS, malaria and tuberculosis combined. ${ }^{3}$ Injuries are mainly from road traffic accidents, and disproportionately affect the young population. ${ }^{4}$

For every death from injury, many more people are living with disability, contributing to the vicious cycle of poverty and reduced productivity. ${ }^{3}{ }^{5}$ Considerable mortality and morbidity can be avoided with prompt and appropriate trauma and orthopaedic $(\mathrm{T} \& \mathrm{O})$ care. Lower extremity injury can be a devastating event in LMICs due to reduced access to modern orthopaedic care. Chagomerana et al found a mortality rate of $9.0 \%$ in patients treated with traction and a mortality rate of $1.3 \%$ in patients treated with surgery in Malawi. ${ }^{6}$ If all-cause injury mortality can be reduced to the level in high-income countries, 50 million disability-adjusted life years and $\$ 786$ billion could be saved annually. ${ }^{4}$ 
Some programmes have been introduced to improve road safety, along with education and training of health professionals, and these have addressed some of the inequality issues. However, further work is needed to explore what resources are required to provide $\mathrm{T} \& \mathrm{O}$ care in LMICs. ${ }^{7}$ Stephens et al found that only $58 \%$ of patients admitted with the intention of definitive T\&O surgical care received surgery due to resource constraints. ${ }^{8}$ Deficient surgical equipment and supplies often limit access to surgical care. The WHO guidelines for essential trauma care has also recognised the need for a specific equipment list. ${ }^{9}$

There is a lack of recommendation on what essential equipment is required in healthcare systems with limited resources. This may lead to absence of equipment, or acquisition of inappropriate equipment. Without the provision of appropriate equipment, training of national T\&O surgeons and other healthcare providers can be wasteful as they are disempowered from caring for the injured by lack of equipment. To address this gap, we wanted to provide an expert consensus on the essential equipment that is required to provide $\mathrm{T} \& \mathrm{O}$ care at different levels of surgical providers in LMICs.

\section{AIM}

We aimed to produce a reference list of essential and desirable equipment for T\&O providers in LMICs. The list is intended to guide governments, healthcare providers and donors regarding the necessary equipment to be able to provide timely and appropriate care of fractures and orthopaedic conditions encountered at facilities in LMICs in sub-Saharan Africa. Similar principles are likely to apply in LMICs outside Africa. This list will be a core set of equipment required, as well as a list of desirable but not essential equipment, to give care providers advice on further useful equipment if they can go beyond the core essentials. We hoped these lists will be available for all those who participate in the supply chain management. We provided a generic list with no company affiliation and allow health providers to purchase from companies in their range of affordability.

\section{METHOD}

We used the Delphi method for this study to generate a consensus statement of essential equipment for $\mathrm{T} \& \mathrm{O}$ care at different levels of care. ${ }^{1011}$ The Delphi method is used to elicit consensus on a given topic. A two-round Delphi study was used with a group of experts answering two web-based questionnaires through Google forms. ${ }^{12}$ The timing between the two questionnaires was 30 days. ${ }^{13}$

We provided the experts with definitions of what we mean by equipment, essential equipment and desirable equipment.

\section{Definitions}

'Equipment' is a reusable item which facilitates fracture and orthopaedic care, and is specific to T\&O. We did not consider hospital furniture items unless they were specific to $\mathrm{T} \& \mathrm{O}$ care-for example, a traction table for fracture surgery was included, but an operating table was not. We did not list consumable items, but some equipment listed requires appropriate consumables and it was understood that a supply of appropriate consumables would be required.

'Essential equipment' is an item of equipment considered to be essential by $75 \%$ or more of the experts who responded.

'Desirable equipment' is an item that does not reach consensus for being an essential equipment but does achieve $75 \%$ or more when considering 'definitely' or' possibly include' together.

Three independent experts, each with over 15 years' experience in T\&O surgery were asked to verify the definitions used for different levels of provider institution, and to generate a list of possible essential equipment for selection in the questionnaire. Definitions used for each tier of provider were as listed below.

\section{Tiers of provider}

'Non-operative based provider': such a centre would not have a specialist $\mathrm{T} \& \mathrm{O}$ surgeon, but care would be given by general doctors or paramedics such as Orthopaedic Clinical Officers.

'Specialist provider with operative fracture care': such a centre would have one to three T\&O or general surgeons with specific training in operative fracture care. It may receive residents but would not oversee its own residency programme in $\mathrm{T} \& \mathrm{O}$.

'Tertiary provider with operative fracture care and orthopaedics': such a centre would be a referral centre for T\&O and a resident teaching centre as well. It would normally be staffed by four or more specialist $\mathrm{T} \& \mathrm{O}$ surgeons, with some available subspecialty expertise (pelvic and acetabulum, hand surgery, etc).

Spine and craniomaxillofacial surgery was omitted as their inclusion would have been too broad.

A group of 34 trained T\&O surgeons in Africa who serve regularly as faculty on fracture care education courses in LMICs were invited to answer the questionnaire. These selected experts work in 13 sub-Saharan African countries. Eighteen work at a tertiary hospital level and 15 at a specialist provider level. From round 1, we received 23 responses from 11 different African countries. The respondents included $52 \%$ from specialist tertiary centres and $48 \%$ of respondents from specialist provider centres. We received 20 expert responses in round 2 from 10 different countries. The round 2 respondents included $55 \%$ from specialist tertiary centres and $45 \%$ of respondents from specialist provider centres.

The questionnaire was designed by one of the authors (WJH) who has 20 years of experience of T\&O surgery in LMICs. The responses were analysed by $\mathrm{YC}$ who has no previous experience of or connections with $\mathrm{T} \& \mathrm{O}$ surgery in LMICs but is familiar with the Delphi technique. The responders were anonymous but were requested to identify 
their country of regular work. Experts were each assigned a number and kept their number throughout the process.

We sent out a web-based questionnaire explaining our aims and instructions as follows:

'Our aim is to produce an essential equipment list for fracture care and orthopaedic provider institutions. Please mark your preference from 'definitely exclude' to 'definitely include', against each equipment item for each of the three tiers of care provider. It should be assumed that equipment would be accompanied by appropriate implants/ consumables with an ongoing supply. Please do not leave any blanks. There is free text space where you can give suggestions of other essential equipment or indicate any questions that are not clear as well as to give reasoning for your response. If your response is neutral, please provide further feedback as to why.'

The responses were graded by the experts on a five-point Likert scale. ${ }^{13}$ The options on the scale were as follows: definitely exclude, possible exclude, neutral, possibly include, definitely include. 'Possibly include' and 'definitely include' were counted towards consensus. Responses 'definitely exclude' and 'possibly exclude' counted towards an item being dropped.

Items which did not fulfil either criterion of definitely include or definitely exclude were brought forward to the next phase with specific feedback on the lack of consensus reached for the item to try and clarify consensus. Thus, in round 2, the same questionnaire was proposed to the expert group minus all items which had $75 \%$ of experts selecting 'definitely exclude'. In addition, experts were now given feedback regarding which items had so far achieved $75 \%$ consensus for inclusion. The experts could select differently in the second round as their 'final decision' with the benefit of allowing the experts to narrow down the essential equipment based on the feedback after round 1 .

Quantitative data including the mean, median and the frequency distribution of each option for each item were sent to the participants after round 1 . Thus, participants were able to see which items were heading towards being included in the essential or desirable equipment list as well as which items were going to be dropped. In round 2, we specifically named which additional items were added from the expert suggestions after round 1.

After round 2, any items still left neutral at this point were now dropped. Items which reached $75 \%$ 'definitely include' were classed as essential equipment. Any item which did not reach $75 \%$ 'definitely include' but reached $75 \%$ consensus when 'definitely include' and 'possibly include' were counted together contributed to a list of desirable but not essential equipment. Equipment items for which opinion was sought have been listed on the main result table (see table 1).

\section{Patient and public involvement}

No patient or public involvement was required in this study.

\section{RESULTS}

\section{Results from round 1}

All the items were carried forward to the second round in the specialist provider and tertiary centre tiers of care. Only the non-operative-based provider had 16 items excluded from round 1. We included five additional items for round 2 voting. These are shown as the last five equipment items in table 1.

\section{Results from round 2}

The final list of essential and desirable equipment for each tier is shown in table 2. For the non-operative provider, the essential equipment related to things that are required for non-operative treatment such as traction and plaster casts. Essential equipment for the specialist provider included equipment for operative intervention, such as the small fragment set, large fragment set, SIGN/rush nailing, external fixators, $\mathrm{K}$ wiring set as well as large cannulated screws. It did not include the full complement of surgical kit offered for selection as these centres are less likely to be performing the full complement of surgical interventions. The majority of equipment for selection was recommended as essential for a tertiary provider with the remaining three equipment being listed as desirable. The essential equipment for tertiary provider included total hip and knee sets as well as reduction clamps for pelvic operations as these centres would potentially be able to offer these types of operations.

\section{DISCUSSION}

People in LMICs lack access to basic surgical care, and surgical systems remain severely under-resourced in these areas, despite evidence that surgical care can be cost-effective and reduce mortality. ${ }^{14}$ By using the Delphi method, we recruited 20 experts, all of whom working in LMICs, to come up with recommendations for a list of essential and desirable equipment for three different levels of care provider (non-operative-based provider, specialist provider with operative fracture care and tertiary centre with operative fracture care and orthopaedics).

This study provides consensus recommendation on essential equipment for $\mathrm{T} \& \mathrm{O}$ care in LMICs. These recommendations will be useful for resource planning at different levels of T\&O care. LMIC policy-makers and budget providers can use these recommendations when planning current and future T\&O care needs. These lists empower $\mathrm{T} \& \mathrm{O}$ providers to assess whether they have the essential equipment required at each provider institution. In many LMICs, T\&O care is deficient at all levels of provider and faces resource limitations. Deficiencies include infrastructure, supplies and human resources. ${ }^{15-17}$ Spiegel et al found availability of uninterrupted open treatment of fractures in hospitals with $\leq 100$ beds to be $17 \% .{ }^{16}$ We wanted our recommendations to be part of the broader work that is guiding allocation of resources required at different levels of care. Our study focuses on T\&O equipment, which to date has been a neglected aspect of policy development. 
Table 1 Results after round 2

\section{Items included in questionnaire}

Non-operative provider Specialist provider Tertiary provider

Traction operating table

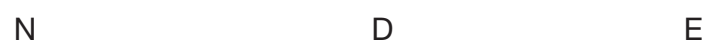

C-arm image intensifier

$\mathrm{N}$

E

Power drill-fully sterilisable

$\mathrm{N}$

Power saw-fully sterilisable

E

$\mathrm{E}$

E

$\mathrm{N}$

D

E

Power drill-handyman type (hardware store) with sterile $\mathrm{N}$

E

cover

Hand drill

\section{$\mathrm{D}$}

T handle

Small fragment plating set

Large fragment plating set

Dynamic hip screw (DHS) instrument set

Hip hemiarthroplasty set

SIGN nailing set

Tibial nail set (not SIGN)-locking

Femoral nail set (not SIGN)-locking

Femoral reconstruction nail set (not SIGN)

Proximal femoral nail set (ie, Gamma nail)

Large cannulated screws

Small cannulated screws

Mini fragment (hand) plating set

Locking plating set (upper limb)

Locking plating set (lower limb)

Large external fixator set (lower limb)

Small external fixator set (upper limb)

Rush nail set

K-wire and cerclage wiring set

Cable set with tensioners

Flexible nail set (for children's fractures)

Total hip replacement set

Total knee replacement set

Knee arthroscopy equipment

$\mathrm{ACL}$ reconstruction equipment

Large basic orthopaedic set (including large size nibblers,

bone cutters, osteotomes, mallet, forceps, retractors,

needle holders)

Small basic orthopaedic set (including small size nibblers, N

D $\quad E$

N E

N $\quad$ E

N $\quad$ E

N $\quad$ D

N

N D

N D

N $D$

N D

N

N

N D

N $\quad$ D

$\begin{array}{lll}N & D & E\end{array}$

N E

N $\quad$ E

$\begin{array}{lll}N & \text { E } & \text { E }\end{array}$

N E

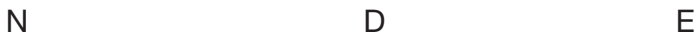

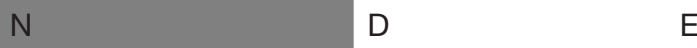

N $\quad$ E

$\mathrm{N} \quad \mathrm{E}$

N $\quad$ E

$\mathrm{N} \quad \mathrm{D}$

$\mathrm{E}$

E

bone cutters, osteotomes, toffee hammer, forceps,

retractors, needle holders)

Fine instrument soft tissue set (including small forceps, N needle holders, etc, suitable for hand surgery and similar)

Large fracture reduction clamp set

Small fracture reduction clamp set

$\mathrm{N}$

$\mathrm{N}$

E $\quad E$

Specific pelvic reduction clamps

$\mathrm{N}$

$\mathrm{E}$

D

Humby knife for harvesting split skin graft

$\mathrm{N}$

Electric or air-powered dermatome for harvesting split skin $\mathrm{N}$

E graft

Mesher for split skin graft

N

E 


\section{Table 1 Continued}

\begin{tabular}{|c|c|c|c|}
\hline Items included in questionnaire & Non-operative provider & Specialist provider & Tertiary provider \\
\hline Traction pulleys & $E$ & $E$ & $E$ \\
\hline Braun frame for limb elevation and traction & $E$ & $E$ & $E$ \\
\hline $\begin{array}{l}\text { Vacuum-assisted wound closure-company purpose- } \\
\text { made version }\end{array}$ & $\mathrm{N}$ & $\mathrm{D}$ & $\mathrm{E}$ \\
\hline Specialist radiolucent operating table & $\mathrm{N}$ & $\mathrm{D}$ & $E$ \\
\hline Electric plaster saw & $E$ & $\mathrm{E}$ & $\mathrm{E}$ \\
\hline Manual plaster saw & $E$ & $\mathrm{E}$ & $\mathrm{D}$ \\
\hline Gigli saw & $\mathrm{N}$ & $E$ & $E$ \\
\hline
\end{tabular}

Blue highlighted items were added after round 1; grey highlighted items were excluded after round 1.

$\mathrm{D}$, desirable; $\mathrm{E}$, essential; $\mathrm{N}$, not recommended; $\mathrm{ACL}$, anterior cruciate ligament.

The WHO guidelines for essential trauma care recognised the need for an equipment list but they do not have an essential T\&O equipment list such as the one that is proposed in this study within their guidelines. ${ }^{9}$ They deemed immobilisation and splinting resources to be essential even at basic level of care. They stated the following procedures should be essential at tertiary and specialist hospitals with orthopaedic surgeons: closed manipulation and casting, skeletal traction, external fixation, internal fixation, irrigation and debridement of complex extremity wounds including open fractures. They also recognised other procedures need to be considered such as management of injured hands, tendon laceration, compartment syndrome and amputation. They stated the relevant equipment must not only be physically present but also promptly available to all who urgently need it. Any worn out or broken equipment must be repaired or replaced.

WHO categorises physical resources into diagnostic equipment, implants and operative equipment. We did not address implants in our study as we considered them to be consumables. We wanted to address operative equipment that can provide essential T\&O care. We also did not look at diagnostic equipment except for a C-arm image intensifier as this is required to enable some of the operations to be carried out safely within the operating theatres.

We have recommended that equipment for casting and traction as essential for non-operative care providers; however, WHO guidelines for essential care recommendations are mainly for the initial management of trauma particular immobilisation and initial haemorrhage control. They have recommended closed reduction and skeletal traction as something that is possibly required at the non-operative level. We did not look at the equipment required for the initial management of trauma but more specifically at the management of orthopaedic trauma beyond the initial management. For a specialist level provider, they have recommended all the surgical procedures including closed reduction, skeletal traction, wound management, internal and external fixation, hand debridement/fixation and tendon repair as essential.

Our essential equipment for specialist providers would cover all these procedures. The WHO has listed one procedure as desirable which is fasciotomy for compartment syndrome and this would still be covered by a basic surgical set which we have included as part of the essential equipment list. Dealing with the sequalae after the initial fasciotomy may require more specialist equipment such as a vaccum assisted closure (VAC) dressing or skin grafting which we have listed as part of our essential equipment for specialist providers. A specialist provider would have an orthopaedic surgeon and general surgeons particularly those with expertise in vascular surgery would be able to diagnose and perform fasciotomies if required, and therefore, we feel that equipment for fasciotomy should be available.

In tertiary level centres, the majority of operative interventions should be available to patients. Both the WHO list of procedures and our equipment list reflects this and most equipment is available at tertiary centres. One point we partially disagree on is the need for image intensifier. WHO has stated it is desirable, whereas, we feel that it is essential. However, their decision for this is due to cost constraints; otherwise, they do recognise that an image intensifier should be an essential equipment. ${ }^{9}$ Manufacturers in middle-income countries can now provide such equipment at vastly reduced costs, and thus, we feel an image intensifier should be an essential equipment.

All healthcare systems require constant monitoring and assessment to determine economics and outcomes. Healthcare should be evidence based. The impact of availability of essential equipment on outcomes, for example, on the number of surgeries performed for those where surgery is indicated, requires audit in the future. 
Table 2 Final list of essential and desirable equipment from trauma and orthopaedic care in LMICs

\begin{tabular}{ll} 
Essential equipment list & Desirable equipment list \\
\hline Non-operative provider & \\
- Electric plaster cast saw & Hand drill \\
- Manual plaster cast saw & Thandle \\
Traction pulleys &
\end{tabular}

Specialist provider

- Power drill-fully sterilisable

- Power drill-handyman type (hardware store) with sterile cover

- Electric plaster cast saw

- Manual plaster cast saw

- Gigli saw

- T handle

- Small fragment plating set

- Large fragment plating set

- Dynamic hip screw (DHS) instrument set

- SIGN nailing set

- Large cannulated screws

- Large external fixator set (lower limb)

- Small external fixator set (upper limb)
- C-arm image intensifier

\section{- Rush nail set}

- K-wire and cerclage wiring set

- Large basic orthopaedic set (including large size nibblers, bone cutters, osteotomes, mallet, forceps, retractors, needle holders)

- Small basic orthopaedic set (including small size nibblers, bone cutters, osteotomes, toffee hammer, forceps, retractors, needle holders)

- Fine instrument soft tissue set (including small forceps, needle holders, etc, suitable for hand surgery and similar)

- Amputation set

- Large fracture reduction clamp set

- Small fracture reduction clamp set

- Humby knife for harvesting split skin graft

- Mesher for split skin graft

- Traction pulleys

- Braun frame for limb elevation and traction

- Vacuum-assisted wound closure-'home made' with portable suction
- Traction operating table

- Specialist radiolucent table

- Power saw-fully sterilisable

- Hand drill

- Hip hemiarthroplasty set

- Tibial nail set (not SIGN)-locking

- Femoral nail set (not SIGN) - locking

- Femoral reconstruction nail set (not SIGN)

- Proximal femoral nail set (ie, Gamma nail)

- Small cannulated screws

- Mini fragment (hand) plating set

- Locking plating set (upper limb)

- Locking plating set (lower limb)

- Cable set with tensioners

- Flexible nail set (for children's fractures)

- Specific pelvic reduction clamps

- Electric or air powered dermatome for harvesting split skin graft

- Vacuum-assisted wound closure-company purpose-made version

- Large femoral distractor

Tertiary provider

- Traction operating table

- Specialist radiolucent table

- C-arm image intensifier

- Power drill-fully sterilisable

- Power saw-fully sterilisable

- Electric plaster cast saw

- Gigli saw

- T handle

- Small fragment plating set

- Large fragment plating set

- Dynamic hip screw (DHS) instrument set

- Hip hemiarthroplasty set

- SIGN nailing set

- Tibial nail set (not SIGN) - locking

- Femoral nail set (not SIGN) - locking

- Femoral reconstruction nail set (not SIGN)

- Proximal femoral nail set (ie, Gamma nail)

- Large cannulated screws

- Small cannulated screws

- Mini fragment (hand) plating set

- Locking plating set (upper limb)

- Locking plating set (lower limb)

- Large external fixator set (lower limb)
- Small external fixator set (upper limb)

- Rush nail set

- K-wire and cerclage wiring set

- Cable set with tensioners

- Flexible nail set (for children's fractures)

- Total hip replacement set

- Total knee replacement set

- Knee arthroscopy equipment

- Large basic orthopaedic set (including large size nibblers, bone cutters, osteotomes, mallet, forceps, retractors, needle holders)

- Small basic orthopaedic set (including small size nibblers, bone cutters, osteotomes, toffee hammer, forceps, retractors, needle holders)

- Fine instrument soft tissue set (including small forceps, needle holders, etc, suitable for hand surgery and similar)

- Amputation set

- Large fracture reduction clamp set

- Small fracture reduction clamp set

- Specific pelvic reduction clamps

- Humby knife for harvesting split skin graft

- Electric or air powered dermatome for harvesting split skin graft

- Mesher for split skin graft

- Traction pulleys

- Braun frame for limb elevation and traction

- Vacuum-assisted wound closure-'home made' with portable suction

- Vacuum-assisted wound closure-company purpose-made version

- Large femoral distractor
The equipment items listed are available from numerous commercial suppliers with different levels of quality and price. The exception in our list is the SIGN nail system ${ }^{18}$ and we allowed this exception since this system is made available without cost for trained providers in LMICs. These lists provide a standard against which potential suppliers 
can tender, such that providers can make effective and affordable decisions. Our stratification of equipment needs for different levels of provider helps target funding at the correct level and can save waste in purchasing unnecessary equipment. Availability of advanced equipment in more basic care facilities not only wastes resources but can be dangerous, as staff in these facilities are not trained to use them correctly. It has also been shown that in LMICs, less than $50 \%$ of facilities had the capacity to repair or maintain equipment which again would be a waste of resources for advanced equipment. ${ }^{19}$ Equally trained surgeons treating complex injuries cannot do so safely unless they have the range of equipment specified in these lists. These lists thus promote both a focus in resource allocation and a safety parameter.

\section{Limitations}

We recognise several limitations in this study. Multiple factors affect access to, and quality of care for, trauma patients. This study only looks at the need to agree on and provide appropriate equipment. In using the Delphi technique, we used the standard Delphi technique and not the modified technique which encompasses a face-to-face meeting between the experts. Our experts all came from Africa and the lists are designed for sub-Saharan Africa. Although they may have application across all LMICs, this has not been tested. We did not specify the number of each equipment item that would be required. Clearly, this will depend on the volume of patient throughput at each institution. The three levels of service provider specified may not exactly be present in all healthcare systems in Africa. The definitions were devised by the senior author who has extensive experience in many African countries. Nevertheless, we accept that minor adjustment may be required to fit the lists to some healthcare systems.

\section{CONCLUSION}

These recommendations have the potential to improve T\&O care in LMICs. The equipment lists proposed are reasonable and feasible for LMICs healthcare systems. Indeed, it should be questioned whether countries can afford not to care for injured persons in an appropriate and timely fashion.

Acknowledgements Many thanks to the experts who participated in our questionnaire: Dr Jes Bates, Malawi, Dr Nicholas Lubega, Malawi, Dr Wilfred Addo, Ghana, Dr Vincent Ativor Ghana, Dr Neford Ongaro, Kenya, Dr Worku Bailey, Ethiopia, Dr Sami Hailu, Ethiopia, Dr Deo Manyama, Tanzania, Dr Joseph Mwanga, Tanzania, Dr Boston Munthali, Malawi, Dr Prem Yohannan, Mozambique,Dr John Ekure, Uganda, Dr Henry Ndasi, Cameroon, Dr James Munthali, Zambia, Dr Samuel Maina, Malawi, Dr Foster Amponsah, Ghana, Dr Kevin Lakati, Kenya, Dr Yirga Mnewer, Ethiopia, Dr Francis Mbugua, Kenya, Dr Kebba Marenah, Gambia.

Contributors $\mathrm{YC}$ was involved in the design of the study, data collection and analysis and writing of the manuscript. LB was involved in the design of the study and editing of the manuscript. CM was involved in the design of the study and editing of the manuscript. WJH was involved in the design of the study and questionnaire, data collection, writing and editing of the manuscript.

Funding The authors have not declared a specific grant for this research from any funding agency in the public, commercial or not-for-profit sectors.

Competing interests None declared.

Patient consent Not required.

Provenance and peer review Not commissioned; externally peer reviewed.

Data sharing statement Questionnaire and data from questionnaire are available upon request.

Open access This is an open access article distributed in accordance with the Creative Commons Attribution Non Commercial (CC BY-NC 4.0) license, which permits others to distribute, remix, adapt, build upon this work non-commercially, and license their derivative works on different terms, provided the original work is properly cited, appropriate credit is given, any changes made indicated, and the use is non-commercial. See: http://creativecommons.org/licenses/by-nc/4.0/.

\section{REFERENCES}

1. Alkire BC, Raykar NP, Shrime MG, et al. Global access to surgical care: a modelling study. Lancet Glob Health 2015;3:e316-e323.

2. Shrime MG, Bickler SW, Alkire BC, et al. Global burden of surgical disease: an estimation from the provider perspective. Lancet Glob Health 2015;3(Suppl 2):S8-9.

3. WHO. Global Health Observatory data: World Health Organization, 2018. (accessed 24 Feb 2018).

4. Agarwal-Harding KJ, von Keudell A, Zirkle LG, et al. Understanding and addressing the global need for Orthopaedic Trauma Care. $J$ Bone Joint Surg Am 2016;98:1844-53.

5. Young S. Orthopaedic trauma surgery in low-income countries. Acta Orthop Suppl 2014;85:1-35.

6. Chagomerana MB, Tomlinson J, Young S, et al. High morbidity and mortality after lower extremity injuries in Malawi: A prospective cohort study of 905 patients. Int J Surg 2017;39:23-9.

7. McQueen KA, Hyder JA, Taira BR, et al. The provision of surgical care by international organizations in developing countries: a preliminary report. World J Surg 2010;34:397-402.

8. Stephens T, Mezei A, O'Hara NN, et al. When surgical resources are severely constrained, who receives care? Determinants of access to Orthopaedic Trauma Surgery in Uganda. World J Surg 2017;41:1415-9.

9. Mock CL, Goosen JD, Joshipura J, et al. Guidelines for essential trauma care. Geneva: World Health Organisation, 2004.

10. Linstone $\mathrm{H}$. The Delphi survey: method techniques and applications: reading: Addison-Wesley, 1975.

11. Diamond IR, Grant RC, Feldman BM, et al. Defining consensus: a systematic review recommends methodologic criteria for reporting of Delphi studies. J Clin Epidemiol 2014;67:401-9.

12. Harrison WJ, Chan Y. Questionnaire conducted using Google Surveys. 2017

13. McMillan SS, King M, Tully MP. How to use the nominal group and Delphi techniques. Int J Clin Pharm 2016;38:655-62.

14. Knowlton LM, Chackungal S, Dahn B, et al. Liberian surgical and anesthesia infrastructure: a survey of county hospitals. World J Surg 2013;37:721-9.

15. Linden AF, Sekidde FS, Galukande M, et al. Challenges of surgery in developing countries: a survey of surgical and anesthesia capacity in Uganda's public hospitals. World J Surg 2012;36:1056-65.

16. Spiegel DA, Nduaguba A, Cherian MN, et al. Deficiencies in the availability of essential musculoskeletal surgical services at 883 health facilities in 24 low- and lower-middle-income countries. World J Surg 2015;39:1421-32.

17. Funk LM, Weiser TG, Berry WR, et al. Global operating theatre distribution and pulse oximetry supply: an estimation from reported data. Lancet 2010;376:1055-61.

18. Shah RK, Moehring HD, Singh RP, et al. Surgical Implant Generation Network (SIGN) intramedullary nailing of open fractures of the tibia. Int Orthop 2004;28:163-6.

19. Hsia RY, Mbembati NA, Macfarlane S, et al. Access to emergency and surgical care in sub-Saharan Africa: the infrastructure gap. Health Policy Plan 2012;27:234-44. 